\title{
Design of peptides with strong binding affinity to poly(methyl methacrylate) resin by use of molecular simulation-based materials informatics
}



Received: 29 May 2021 / Revised: 5 July 2021 / Accepted: 6 July 2021 / Published online: 5 August 2021

(c) The Author(s) 2021. This article is published with open access

\begin{abstract}
Peptides with strong binding affinities for poly(methyl methacrylate) (PMMA) resin were designed by use of materials informatics technology based on molecular dynamics simulation for the purpose of covering the resin surface with adhesive peptides, which were expected to result in eco-friendly and biocompatible biomaterials. From the results of binding affinity obtained with this molecular simulation, it was confirmed that experimental values could be predicted with errors $<10 \%$. By analyzing the simulation data with the response-surface method, we found that three peptides (RWWRPWW, EWWRPWR, and RWWRPWR), which consist of arginine (R), tryptophan (W), and proline (P), have strong binding affinity to the PMMA resin. These amino acids were effective because arginine and tryptophan have strong binding affinities for methoxycarbonyl groups and methyl groups, which are the main constituents of the PMMA resin, and proline stabilizes the flat zigzag structures of the peptides in water. The strong binding affinities of the three peptides were confirmed by experiments (surface plasmon resonance methods).
\end{abstract}

\section{Introduction}

As computer power has been greatly improved, various simulations methods, such as quantum mechanics and molecular dynamics simulations, have been used to design materials. However, most simulation-based designs tend to involve computational trial and error approaches. For example, researchers often simulate many candidate materials and have to choose from among a large number of materials to identify a material that satisfies the required characteristics, so the efficiency is not very high. Therefore, materials informatics (MI) technology has been developed to find appropriate materials by combining molecular dynamics simulation [1-10] and a response-surface method [11-13]; the latter is often used for optimizing the sizes and shapes of mechanical structures such as fan blades and

Tomio Iwasaki

tomio.iwasaki.ka@hitachi.com

1 Research \& Development Group, Hitachi, Ltd, Hitachishi, Ibaraki, Japan

2 School of Materials and Chemical Technology, Tokyo Institute of Technology, Meguro-ku, Tokyo, Japan propellers in air conditioner condensers. In this technology, the data from molecular simulations [1-10], which are now accurate enough to express physical and chemical properties of materials due to improvements in simulation technology, are analyzed by use of a response-surface method (Kriging method). This analysis of data makes it possible to express an objective property as a function of dominant parameters and allows one to find the materials that best maximize that property. This MI technology is applicable to the design of other functional molecules such as peptides, which are promising biomaterials.

Recently, methods of medical treatment have been diversified, and it has become more common in the biomedical field to put therapy biodevices and artificial organs into the body or to use them as wearable devices in contact with the skin [14]. However, if the materials used for biodevices and artificial organs are not biocompatible, problems such as inflammation of the body part in contact with these materials will occur [15]. Therefore, studies have been conducted to prevent problems such as inflammation by attaching bio(macro)molecules to the surfaces of resin (plastic) materials and inorganic materials used for biodevices and artificial organs because bio(macro)molecules are often biocompatible and eco-friendly materials [16, 17]. Peptides that specifically attach to materials in a 
noncovalent manner are excellent candidates for this purpose [18-20]. However, not all peptides have strong binding affinities for the materials, and this depends on the species of the materials. Therefore, appropriate peptides must be selected or designed for each material.

This paper describes the application of MI technology to the efficient design of peptides (amino acid sequences) that have strong binding affinities for polymeric materials. As a proof of concept, we used an isotactic polymethylmethacrylate (PMMA) resin [21], which is relatively inexpensive and does not deteriorate easily, and we tried to efficiently design peptides with strong binding affinities for the PMMA resin by analyzing data from computer molecular simulations [22-27] with the response-surface method (Kriging method). As a result of this design, it was found that three peptides (RWWRPWW, EWWRPWR, and RWWRPWR), which consist of arginine (R), tryptophan $(\mathrm{W})$, and proline $(\mathrm{P})$, have strong binding affinities for the PMMA resin. Because the strong binding affinity of each peptide was confirmed by experiments (surface plasmon resonance (SPR) methods), MI technology is considered effective for designing peptides with strong binding affinities for resins. It is expected that this technology will be applied not only to the design of other biomaterials, such as proteins and nucleic acids, but also to the design of ecofriendly materials, such as biodegradable plastics and rubbers.

\section{Methods}

\section{Method of molecular dynamics simulations}

In the simulations, the position $\mathbf{r}_{\mathrm{i}}$ and velocity $\mathrm{d} \mathbf{r}_{\mathrm{i}} / \mathrm{d} t$ of each atom can be obtained by solving Newton's equation of motion

$m_{\mathrm{i}} \mathrm{d}^{2} \mathbf{r}_{\mathrm{i}} / \mathrm{d} t^{2}=-\partial P / \partial \mathbf{r}_{\mathrm{i}}$

where $m_{\mathrm{i}}$ and $\mathbf{r}_{\mathrm{i}}$ are the atomic mass and atomic position of the $\mathrm{i}$-th atom, respectively, and $P$ is the potential energy. By using the polymer consistent force field (PCFF) [3-6], this potential energy $P$ is expressed as the sum of bonded interactions and nonbonded interactions in the following equation:

$P=P_{\mathrm{R}}+P_{\theta}+P_{\varphi}+P_{\omega}+P_{\text {cross }}+P_{\mathrm{vdw}}+P_{\mathrm{el}}$

Here, bond stretching $\left(P_{\mathrm{R}}\right)$, bond angle bending $\left(P_{\theta}\right)$, angle torsion $\left(P_{\varphi}\right)$, inversion $\left(P_{\omega}\right)$, and cross terms $\left(P_{\text {cross }}\right)$ are bonded interactions. Cross terms $\left(P_{\text {cross }}\right)$ include stretch-stretch, stretch-bend-stretch, bend-bend, torsion-stretch, torsion-bend-bend, bend-torsion-bend, and stretch-torsion-stretch interactions. On the other hand, van der Waals $\left(P_{\mathrm{vdw}}\right)$ terms and electrostatic $\left(P_{\mathrm{el}}\right)$ terms are nonbonded interactions. Each term of the PCFF potential energy equation was obtained by using a force-matching method $[1,2]$ with atomic forces calculated from quantum mechanics [16, 17]. By solving Newton's equation of motion with the PCFF potential by use of the Verlet algorithm [28], we calculated the atomic positions and velocities in peptides and resins. Calculations were conducted in isothermal-isobaric ensembles (NPT), and the Nose-Hoover method $[29,30]$ with a damping parameter of $100 \mathrm{fs}$ and the Parinello-Rahman method [31] with a damping parameter of $1000 \mathrm{fs}$ were used to keep the target temperature and pressure at $25^{\circ} \mathrm{C}$ and $0.1013 \mathrm{MPa}$. After obtaining calculated results with our inhouse software, we confirmed that the same results were obtained by using the Forcite module with the PCFF potential in Materials Studio from Dassault Systèmes.

\section{Model for analyzing binding affinity between resin and peptide}

Before explaining a simulation model used for calculating the binding affinity, a model of the resin (isotactic PMMA resin) is explained. To obtain the most likely surface structure, two hundred molecules of isotactic PMMA with a molecular weight of 35,500 were initially placed in a $100 \mathrm{~nm}$ cubic simulation cell with positions and orientations set at random, as shown in Fig. 1a. Although the simulation cell contained water, water molecules are not shown in the figures in this paper so the atoms and molecules of interest are not hidden by the water molecules. As a result of the molecular dynamics simulation described before, a PMMA molecular cluster was obtained, as shown in Fig. 1b. The surface of the PMMA cluster shown in Fig. 1b has two surface structures. One is a simple crystalline structure, for which the top and side views are shown in Fig. 1c, d, and the other is a complicated structure comprising grain boundaries and amorphous structures. As shown in Fig. 1b, more than half of the surface has a simple structure. By changing the initial positions and orientations, it was confirmed that surface structures similar to Fig. 1b were obtained. Accordingly, the simple surface structure shown in Fig. 1c, d was the most likely PMMA surface structure. For this reason, a crystalline PMMA particle (Fig. 1e) with the same structure as that in Fig. 1c, d was employed as a PMMA model. Because of the limitation of computer power, the size of the PMMA particle was set at $5 \mathrm{~nm}$. By relaxing this particle model at $25^{\circ} \mathrm{C}$ with the molecular dynamics simulation, the simple and stable crystal structure shown in Fig. 1c, d was observed for the particle model. This crystal structure was divided into two kinds of regions, which are shown in Fig. 1c. In one region, methoxycarbonyl groups $\left(-\mathrm{COOCH}_{3}\right)$ were lined up face to face. In the other region, methyl groups $\left(-\mathrm{CH}_{3}\right.$ groups) were 
(a)

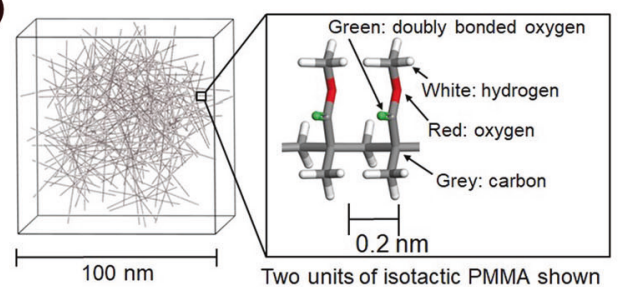

(b)

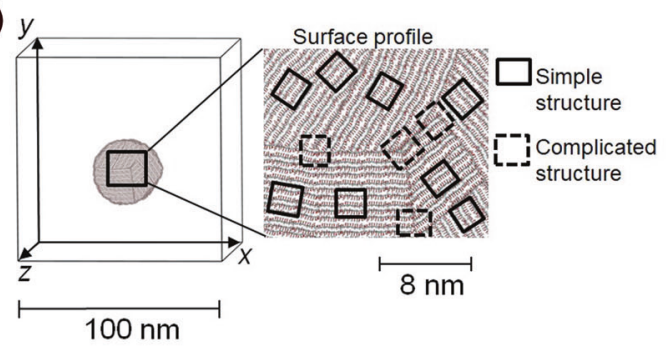

(c)



(d)

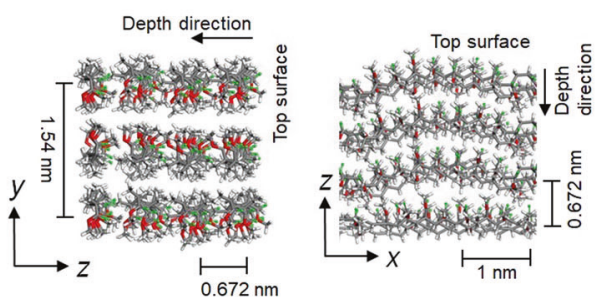

(e)



lined up face to face. The periodicity spacing in the $y$ direction, which is the average distance between the methyl regions $\left(-\mathrm{CH}_{3}\right.$ regions), was $1.54 \mathrm{~nm}$, as shown in Fig. 1c, d.
Fig. 1 a Initial model of two hundred molecules of PMMA with a molecular weight of 35,500, b example of a PMMA molecule cluster obtained with clustering simulation (only the outermost part of the cluster is shown), $\mathbf{c}$ top view of the simple structure of the PMMA surface, $\mathbf{d}$ side views of the simple structure of the PMMA surface, and e outermost part of the $5 \mathrm{~nm}$ PMMA nanoparticle model and association/dissociation of the peptide

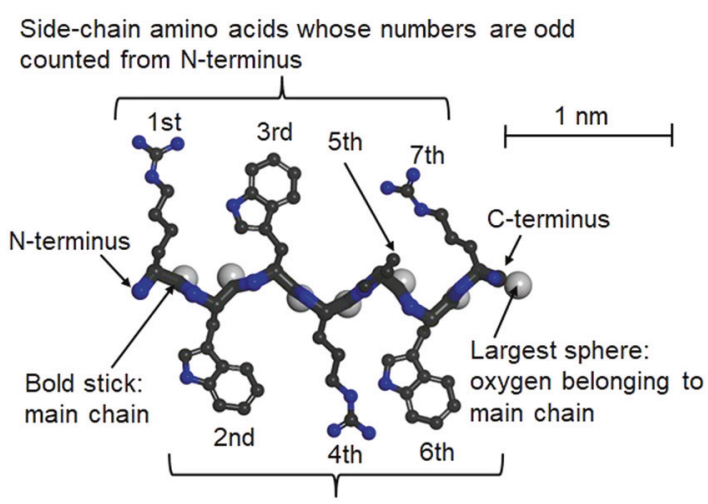

Side-chain amino acids whose numbers are even counted from $\mathrm{N}$-terminus

Fig. 2 Example of a peptide model with seven amino acids

The periodicity spacing in the $z$ direction, which is the average distance between the main chains in the depth direction, was $0.672 \mathrm{~nm}$, as shown in Fig. 1d. The periodicity spacing of this crystal structure in the $x$ direction (the main chain direction), which is the average distance between methoxycarbonyl groups (- $\mathrm{COOCH}_{3}$ groups), was $0.264 \mathrm{~nm}$, as shown in Fig. 1c.

A simulation model for evaluating binding affinities between isotactic PMMA resin and peptides is also shown in Fig. 1e. An example of the peptide model is shown in Fig. 2. In the figures in this paper, the hydrogen atoms of the peptides are not shown to make the atomic configuration easier to see. Amino acids included as side chains in the peptide were located according to experimental results [21]. The number of amino acids was set at seven, which is the same number as that used in a previous paper [21]. In this figure, according to the rule used in this field, the $\mathrm{N}$-terminus with the amino group ( $-\mathrm{NH}_{2}$ group) of a peptide is shown on the left, and the $\mathrm{C}$-terminus with a carboxyl group $(-\mathrm{COOH}$ group) or $-\mathrm{CONH}_{2}$ group of a peptide is shown on the right.

In this study, the $\mathrm{C}$-terminus was set to be the $-\mathrm{CONH}_{2}$ group according to the experimental structure on the phage display. The $\mathrm{N}$-terminal $\mathrm{NH}_{2}$ group was designated as $\mathrm{NH}_{3}{ }^{+}$, reflecting protonation at neutral $\mathrm{pH}$.

\section{Binding affinity calculation by molecular dynamics simulation}

To design peptides with strong binding affinities to the resin (that is, to find a sequence of amino acids with appropriate 
side chains) by using the simulation model in the previous section, it was necessary to evaluate the binding affinity in the simulations. In this study, the binding affinity was evaluated by calculating the binding free energy, which was obtained from the standard free energy change per mole between the associated state and the dissociated state (Fig. 1e) [32-37].

The procedure for calculation of the binding free energy based on the simulation is explained. First, as shown in Fig. 1e, a peptide model was attached to the PMMA resin by initially placing the peptide $2 \mathrm{~nm}$ away from the PMMA surface, and the relaxation calculation was performed at $25^{\circ} \mathrm{C}$ to obtain an associated state. At this time, when the energy change per step ( $1 \mathrm{fs}$ ) became $1 \%$ or less and when the potential energy change for one million steps ( $1 \mathrm{~ns})$ became $2 \%$ or less, it is concluded that the thermodynamic quasi-equilibrium state was reached and the relaxation calculation was completed. This relaxed state is regarded as the associated state. To clarify the dependence of the initial placement of the peptide on these results, the initial positions and orientations of the peptide were randomly changed ten times, and the changes in relaxed interface structures of associated states were investigated by visualizing the structures. By carrying out long-term simulations (100 ns), dissociation and association were observed. The binding free energy was calculated from the standard free energy change between the associated state and the dissociated state [32-37]. The energy values were calculated by averaging over samples of ten $100 \mathrm{~ns}$ simulations for which the initial positions and orientations of the peptide were randomly changed. The standard deviations were also calculated.

\section{Method for designing strongly adhesive peptides by use of MI}

In the MI technology used in this study, the objective property $F$ was expressed as a function $F(\mathrm{~A}, \mathrm{~B}, \mathrm{C}, \ldots)$ of the material characteristic parameters $\mathrm{A}, \mathrm{B}, \mathrm{C}, \ldots$ (which are called descriptors, design variables, etc.) obtained by using simulation data. Then, the optimum material was found from the optimum parameter values by $\mathrm{s}$ finding the maximum of the function $F(\mathrm{~A}, \mathrm{~B}, \mathrm{C}, \ldots)$. To obtain this function $F(\mathrm{~A}, \mathrm{~B}, \mathrm{C}, \ldots)$ from the data of molecular dynamics simulations, the response-surface method was used in this study.

Here, the objective property $F$ is the binding affinity (binding free energy) with the resin, and the parameters A, $\mathrm{B}, \mathrm{C}, \ldots$, which represent the characteristics of the material, are the parameters of peptides. Data were collected by carrying out the molecular dynamics simulations explained in the previous section, and the binding free energy $F$ with the resin was expressed as a function of the characteristic

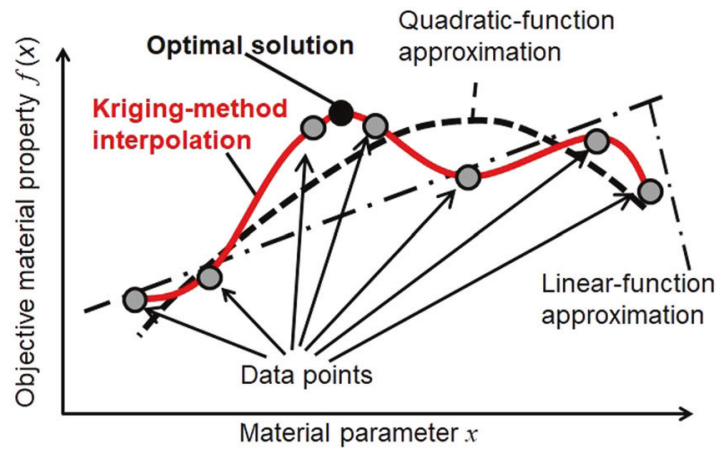

Fig. 3 Schematic view of interpolation based on the Kriging method, which is a response-surface method

parameters $\mathrm{A}, \mathrm{B}, \mathrm{C}, \ldots$ of the peptide by applying the response-surface method to the data. The response-surface method used for functionalization is a method called the Kriging method [11-13]. A schematic view of three interpolation methods is shown in the one-dimensional conceptual diagram (Fig. 3). The Kriging method (bold line in Fig. 3) creates an approximate function by interpolating the data so that all of the data are on the line. The broken line and dashed-and-dotted line in Fig. 3 are well-used linear and quadratic-curve approximations, but the Kriging method can express a finer profile, so it is effective when using data with small variations such as those resulting in the bold line (Kriging method) in Fig. 3. This shows the maximum value, which is the solution for the optimum design. In the case of material design, the optimum design is determined by selecting a material that realizes the parameter values corresponding to this optimum solution. In reality, there may be no material with a parameter value that matches the optimum solution exactly. Even if it does exist, it may not satisfy other properties. Therefore, materials with parameter values close to the optimum solution were selected as candidates.

In the MI design that maximized the strength of adhesion between resins and metals, the mismatch of lattice constants is an important dominant parameter (control factor); strong adhesion was achieved by reducing the mismatch [22-24]. However, in this study, the distances (lattice constant) between side chains of adjacent amino acids of the peptide are $\sim 0.3-0.35 \mathrm{~nm}$ and do not depend on the type of amino acid, so this cannot be changed as a control factor. Therefore, the lattice constant and its mismatch could not be used as control factors. We simply used the detachment energy of the side chain (amino acid) of the peptide with respect to the functional groups of the resin (methoxycarbonyl group, $-\mathrm{COOCH}_{3}$ and methyl group, $-\mathrm{CH}_{3}$ ) as control factors. The detachment energy was defined as the difference between the potential energy of the attached state and that of the detached state. The binding free energy of the peptide/resin interface, which is the objective property, was expressed as 
a function of these control parameters. First, the validity of the simulation was confirmed by comparing the delamination energies from the molecular dynamics simulations with experimental values. Then, the binding free energy was expressed as a function $F(\mathrm{~A}, \mathrm{~B}, \mathrm{C}, \ldots)$ of the detachment energies with respect to the functional groups of the resin, and a peptide that maximizes the binding affinity was designed by finding the maximum.

\section{Measurement of binding affinity with the SPR method}

The experimental determination of binding affinity was carried out by measuring the rate constants for binding and dissociation of the peptide and the resin by use of the SPR method described in a previous study [21]. As shown later in a typical result (Fig. 9a), when the analyte solution was passed over the sensor chip and the peptide was associated with PMMA, the signal due to SPR increased. Then, when the solution containing no adhesive peptide flowed, the peptide associated with PMMA dissociated from PMMA, and the signal decreased, as shown on the right side of the graph (Fig. 9a). By comparing the SPR signal with the time evolution equation

$$
\mathrm{d}[\mathrm{AB}] / \mathrm{dt}=k_{1}[\mathrm{~A}][\mathrm{B}]-k_{-1}[\mathrm{AB}]
$$

the ratio of affinity constants $\left(K_{\mathrm{a}}=k_{1} / k_{-1}\right)$ as well as the association $\left(k_{1}\right)$ and dissociation $\left(k_{-1}\right)$ rate constants were estimated, as shown in ref. [21]. Here, $t$ is the time, [A] and [B] are the concentrations of dissociated peptide and PMMA, respectively, and $[\mathrm{AB}]$ is the concentration of associated peptide-PMMA combinations. As shown in refs. [32-34], the binding free energy for the standard state, $\Delta G_{\mathrm{b}}$, was expressed as in the following equation by using $K_{\mathrm{a}}$, which has the units of inverse concentration $\left(\mathrm{M}^{-1}\right)$.

$$
\Delta G_{\mathrm{b}}=-\Delta G^{0}=N_{\mathrm{A}} k_{\mathrm{B}} T \ln \left(K_{\mathrm{a}} C^{0}\right)=R T \ln \left(K_{\mathrm{a}} C^{0}\right)
$$

Here, $C^{0}$ is the standard-state concentration $(1 \mathrm{M})$, which makes $K_{\mathrm{a}} C^{0}$ dimensionless (unitless); $k_{\mathrm{B}}$ is the Boltzmann constant $\left(1.380649 \times 10^{-23} \mathrm{~J} / \mathrm{K}\right) ; N_{\mathrm{A}}$ is the Avogadro constant $\left(6.02214 \times 10^{23} \mathrm{~mol}^{-1}\right) ; R$ is the gas constant $(8.31447$ $\mathrm{J} \mathrm{mol}^{-1} \mathrm{~K}^{-1}$ ); and $\Delta G^{0}$ is the standard free energy change per mole, as shown in refs. [32-34].

Isotactic, it-PMMA, $\quad(\mathrm{Mn}=23,200, \quad \mathrm{Mw} / \mathrm{Mn}=1.26$, mm:mr:rr = 97:3:0) was purchased from Polymer Source, Inc., located in Montreal, Quebec, Canada, and it-PMMA film was prepared on a gold substrate (SIA Kit AU, GE Healthcare) by spin-coating (2000 rpm). Peptides with a free $\mathrm{N}$-terminus and an amidated $\mathrm{C}$-terminus were used. All peptides (ELWRPTR, RWWRPWW, EWWRPWR, and RWWRPWR) were purchased from GL Biochem (immunograde). The peptides were purified before use with high- performance liquid chromatography (ELITE LaChrom, Hitachi Hitechnologies) with Cosmosil 5C18-AR-300 (Nacalai Tesque) using acetonitrile-water solvents. The peptides were dissolved in $10 \mathrm{mM}$ HEPES buffer ( $\mathrm{pH}$ 7.4) containing $150 \mathrm{mM} \mathrm{NaCl}$ as an analyte solution. Biacore X100 (GE Healthcare) was used for the SPR measurements. The peptide-free buffer was flowed at a rate of $20 \mu \mathrm{L} / \mathrm{min}$ at $25^{\circ} \mathrm{C}$ to stabilize the signal. The analyte solution containing the peptide was flowed onto the surface of the it-PMMA film under the same conditions for 3 min to allow association. Then, peptide-free buffer was flowed for $12 \mathrm{~min}$ under the same conditions to cause dissociation.

\section{Results and discussion}

First, to confirm the effectiveness of the molecular dynamics simulation, experimental results for the binding affinity and simulation results were compared. The free energies for binding between PMMA resin and 12 types of peptides, for which experimental results of $k_{1}, k_{-1}$, and $K_{\mathrm{a}}$ had already been obtained with the SPR method in a previous study [21], were calculated by using the simulation. The simulation results are shown in Table 1 and Fig. 4 together with the experimental data. The symbols in which seven letters, such as ELWRPTR, are lined up, are symbols representing the seven amino acids contained in the peptide, and one letter is given to each amino acid according to the rules used in this field. For example, E stands for glutamic acid, L stands for leucine, $\mathrm{W}$ stands for tryptophan, and $\mathrm{R}$ stands for arginine. There are 20 natural amino acids that make up proteins. The side chain ends of $\mathrm{R}, \mathrm{K}, \mathrm{D}$, and $\mathrm{E}$ are ionized to reflect general protonation/deprotonation at neutral $\mathrm{pH}$. The $\mathrm{N}$-terminus and $\mathrm{C}$-terminus are $\mathrm{NH}_{3}{ }^{+}$and $\mathrm{CONH}_{2}$, respectively, as described above. To describe the amino acid sequence of the peptide, such as ELWRPTR, the $\mathrm{N}$-terminus with the amino group $\left(\mathrm{NH}_{2}\right.$ group) is placed on the left, and the $\mathrm{C}$-terminus with a carboxylic acid group $(-\mathrm{COOH})$ or $-\mathrm{CONH}_{2}$ group is placed on the right.

From the results of Table 1 and Fig. 4, it was confirmed that the binding free energy could be predicted with a molecular dynamics simulation to within a prediction error of $10 \%$. Accordingly, the response-surface method (Kriging method) can be applied to the data of this simulation to design peptides with strong binding affinities.

Here, the free energies for binding of the side chains (amino acids) of the peptide with resin functional groups (methoxycarbonyl groups, $-\mathrm{COOCH}_{3}$, and methyl groups, $-\mathrm{CH}_{3}$, in the case of PMMA resin) were used as parameters characteristic of the peptide/resin interface. The binding free energy was expressed as a function such as $F(\mathrm{~A}, \mathrm{~B}, \mathrm{C} \ldots)$, and a peptide with strong binding affinity to PMMA resin was designed by finding the maximum of the function. 
Table 1 Values of binding free energies, association/dissociation rate constants, and standard deviations

\begin{tabular}{|c|c|c|c|c|c|}
\hline $\begin{array}{l}\text { Amino acid } \\
\text { sequence }\end{array}$ & $\begin{array}{l}\text { Simulated result of } \\
\text { binding free energy } \\
\Delta G_{\mathrm{b}, \mathrm{sim}}(\mathrm{kJ} / \mathrm{mol})\end{array}$ & $\begin{array}{l}\text { Experimental binding free } \\
\text { energy obtained from the } \\
\text { right two columns with } \\
\text { a standard concentration } \\
\text { of } C^{0}=1 \mathrm{M}, \Delta G_{\mathrm{b}, \mathrm{sim}}= \\
R T \ln \left(C^{0} k_{1} / k_{-1}\right)(\mathrm{kJ} / \mathrm{mol})\end{array}$ & $\begin{array}{l}\text { Association rate } \\
\text { constant } k_{1}\left(\mathrm{M}^{-1} \mathrm{~s}^{-1}\right) \\
\text { shown in ref. [21] }\end{array}$ & $\begin{array}{l}\text { Dissociation } \\
\text { rate constant } \\
k_{-1}\left(10^{-3} \mathrm{~s}^{-1}\right) \\
\text { shown in ref. } \\
{[21]}\end{array}$ & $\begin{array}{l}\text { Standard } \\
\text { deviation } \\
\text { of } \Delta G_{\mathrm{b}, \text { sim }} \\
(\mathrm{kJ} / \mathrm{mol})\end{array}$ \\
\hline ELWRPTR & 32.1 & 31.1 & 31 & 0.11 & 0.523 \\
\hline EAWRPTR & 31.6 & 30.8 & 30 & 0.12 & 0.514 \\
\hline ELWRATR & 23.5 & 22.6 & 3.4 & 0.38 & 0.417 \\
\hline QLQKYPS & 26.3 & 24.8 & 13 & 0.58 & 0.436 \\
\hline ELWRPAR & 28.5 & 27.7 & 17 & 0.24 & 0.469 \\
\hline ARPHLSF & 28.3 & 27.5 & 13 & 0.20 & 0.451 \\
\hline SSPWMRE & 28.1 & 27.4 & 15 & 0.24 & 0.442 \\
\hline GIRHTNR & 27.7 & 26.4 & 20 & 0.48 & 0.439 \\
\hline ALWRPTR & 30.2 & 29.3 & 16 & 0.12 & 0.511 \\
\hline ELARPTR & 31.8 & 30.9 & 29 & 0.11 & 0.521 \\
\hline ELWAPTR & 30.9 & 29.6 & 23 & 0.15 & 0.519 \\
\hline ELWRPTA & 29.9 & 28.5 & 13 & 0.13 & 0.508 \\
\hline
\end{tabular}

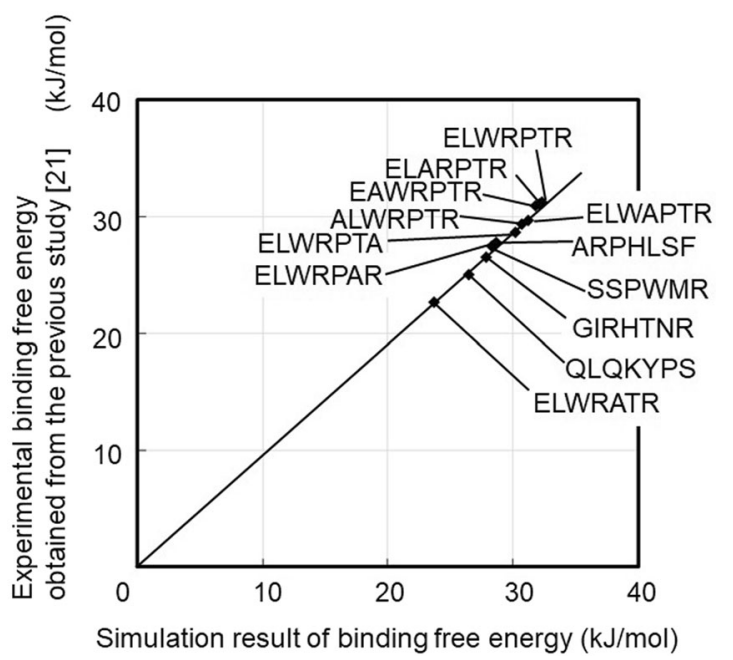

Fig. 4 Comparison of experimental [21] and simulated binding free energies

Table 2 shows calculated detachment energies for functional groups, which provides a characteristic parameter for each amino acid. As seen from this table, the amino acids (i.e., side chains of the peptide) exhibiting high energies for detachment from the methoxycarbonyl $\left(-\mathrm{COOCH}_{3}\right)$ group, which is one of the two functional groups of PMMA resin, were $\mathrm{W}, \mathrm{R}$, and $\mathrm{E}$. On the other hand, amino acids with high energies for detachment from the methyl $\left(-\mathrm{CH}_{3}\right)$ group, which is the other functional group, are $\mathrm{W}$ and $\mathrm{R}$. Therefore, it is roughly expected that amino acids $\mathrm{W}$ and $\mathrm{R}$ will have strong binding affinities. Although the number of amino acids was set at seven, which is the same number used in the
Table 2 Energies for detachment of amino acids from COOCH3 and $\mathrm{CH} 3$

\begin{tabular}{lll}
\hline $\begin{array}{l}\text { Amino acid (side } \\
\text { chain of peptide) }\end{array}$ & $\begin{array}{l}\text { Detachment energy with } \\
\mathrm{COOCH}_{3}(\mathrm{~kJ} / \mathrm{mol})\end{array}$ & $\begin{array}{l}\text { Detachment energy } \\
\text { with } \mathrm{CH}_{3}(\mathrm{~kJ} / \mathrm{mol})\end{array}$ \\
\hline $\mathrm{W}$ & 3.57 & 3.47 \\
$\mathrm{R}$ & 3.51 & 3.49 \\
$\mathrm{E}$ & 3.34 & 2.67 \\
$\mathrm{H}$ & 3.18 & 2.95 \\
$\mathrm{~K}$ & 2.87 & 2.76 \\
$\mathrm{Q}$ & 2.84 & 2.71 \\
$\mathrm{Y}$ & 2.69 & 2.36 \\
$\mathrm{~N}$ & 2.65 & 2.57 \\
$\mathrm{~F}$ & 2.63 & 2.34 \\
$\mathrm{D}$ & 2.57 & 2.15 \\
$\mathrm{M}$ & 2.12 & 1.98 \\
$\mathrm{P}$ & 2.03 & 1.87 \\
$\mathrm{~L}$ & 1.73 & 2.08 \\
$\mathrm{~T}$ & 1.73 & 1.65 \\
$\mathrm{I}$ & 1.54 & 1.37 \\
$\mathrm{~S}$ & 1.28 & 1.03 \\
$\mathrm{~V}$ & 1.24 & 1.66 \\
$\mathrm{C}$ & 1.24 & 1.08 \\
$\mathrm{~A}$ & 1.16 & 1.43 \\
$\mathrm{G}$ & 0.376 & 0.297 \\
\hline & &
\end{tabular}

experiments, these simulations showed that even if the number of amino acids contained in the peptide was not seven, the process of deriving amino acid sequences exhibiting strong binding affinities did not change significantly. 
(a)

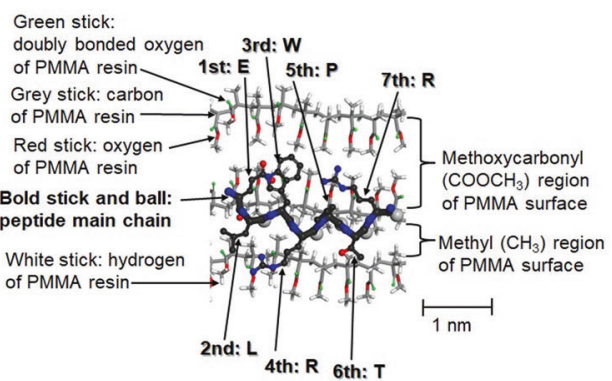

(b)

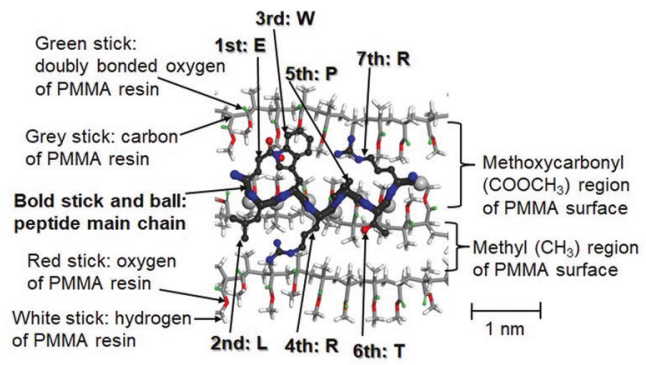

(c)

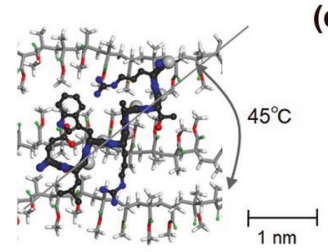

(e)

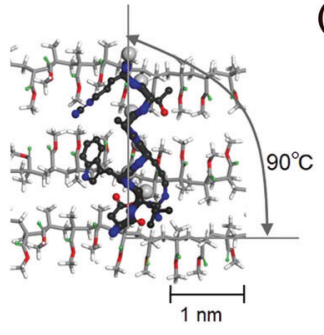

(d)

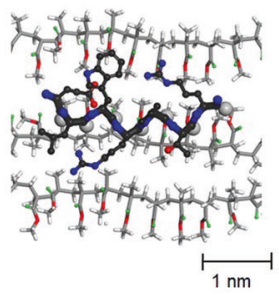

(f)

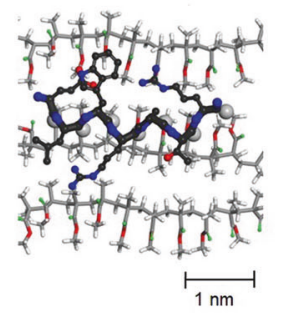

(g)

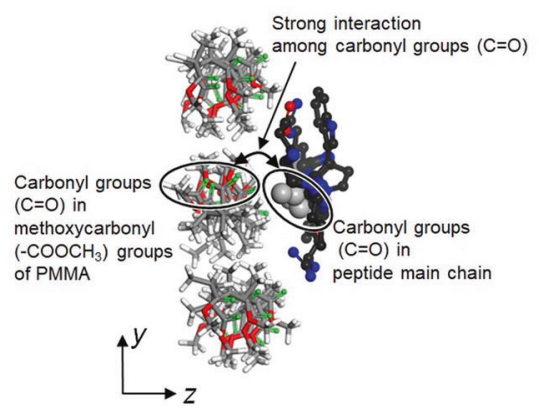

Next, to clarify the optimal sequences of amino acids giving strong binding affinity, we visualized the top view of the interface between the peptide listed at the top of Table 1, i.e., ELWRPTR, and the PMMA resin (Fig. 5a-f). Figure $5 \mathrm{a}, \mathrm{c}$, e shows three examples of the first stages of attachment, which were obtained from different initial positions and orientations of the peptide. The main chain of
Fig. 5 a Example of a top view of the first-stage attachment of ELWRPTR to PMMA, b top view of stable associated state obtained by stabilizing the unstable state shown in (a) for $0.5 \mathrm{~ns}$, c another example of a top view of the first-stage attachment obtained from an initial position and orientation different from those of (a) and (e), $\mathbf{d}$ top view of a stable associated state obtained by stabilizing the unstable state shown in (c) for $0.5 \mathrm{~ns}$, e different example of top view of the first-stage attachment obtained from an initial position and orientation different from those of (a) and (c), $\mathbf{f}$ top view of a stable associated state obtained by stabilizing the unstable state shown in (e) for $0.5 \mathrm{~ns}$, and (g) side view of a stable associated state obtained by stabilizing the unstable state shown in (a) for $0.5 \mathrm{~ns}$

the peptide ELWRPTR in Fig. 5a is almost parallel to the main chain of PMMA, while the main chain of the peptide ELWRPTR in Fig. $5 \mathrm{c}$ is tilted $\sim 45^{\circ}$ from the main chain direction of PMMA. On the other hand, the main chain of the peptide in Fig. 5e is tilted $\sim 90^{\circ}$ from the main chain direction of PMMA. These states (Fig. 5a, c, e) were not stabilized, and the stabilized states in the simulations were obtained $0.5 \mathrm{~ns}$ after these states. The stabilized states obtained from Fig. 5a, c, e are shown in Fig. 5b, d, f, respectively. The interface structures of the stable associated states shown in these figures are found to be almost the same. To clarify the reason that all stable interface structures were nearly equivalent (almost independent of the structure used for the first-stage attachment), the side view of the associated state shown in Fig. $5 \mathrm{~b}$ is presented in Fig. 5g. This figure shows that the carbonyl groups $(\mathrm{C}=\mathrm{O})$ in the peptide main chain were attracted to the carbonyl groups $(\mathrm{C}=\mathrm{O})$ in the methoxycarbonyl $\left(-\mathrm{COOCH}_{3}\right)$ groups of PMMA with strong interactions among $\mathrm{C}=\mathrm{Os}$. This strong interaction is thought to have caused the same interface structures found for stable associated states in Fig. $5 b, d$, f. As seen in these figures, the double-bonded oxygen atoms (largest spheres) in the main chain of the peptide and the odd-numbered amino acids (counting from the $\mathrm{N}$-terminus) were attached to the methoxycarbonyl groups, $-\mathrm{COOCH}_{3}$, of the PMMA resin. On the other hand, the even-numbered amino acids (again counting from the $\mathrm{N}$-terminus) were attached to the methyl groups, $-\mathrm{CH}_{3}$, of the resin. Although the figure is omitted, the associated states of the other peptides in Table 1 also had similar structures. From these results, when the energies for detachment of odd-numbered amino acids (counted from the N-terminus) from $-\mathrm{COOCH}_{3}$ were high, and when the energies for detachment of even-numbered amino acids from $-\mathrm{CH}_{3}$ were high, the free energy for binding between the peptide and the PMMA resin was high.

Based on the above consideration, the sum of the energies for detachment of the odd-numbered amino acids with $\mathrm{COOCH}_{3}$ was set as one parameter, and the sum of the energies for delamination of the even-numbered amino acids with $\mathrm{CH}_{3}$ was set as the other parameter. We tried to express the binding free energy of the peptide with PMMA 


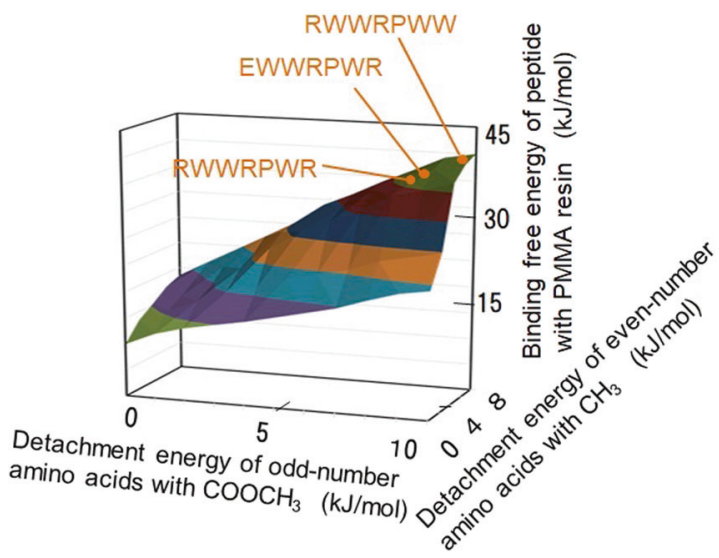

Fig. 6 Binding free energy of peptide/PMMA from a function obtained with the Kriging method

resin as a function of these parameters by using a responsesurface method (Kriging method). The function in Fig. 6 is the result of applying the Kriging method to the data in Table 1. Figure 6 confirms that when the energies for detachment of the odd-numbered amino acids from $-\mathrm{COOCH}_{3}$ were high, and when the energies for detachment of the even-numbered amino acids with $-\mathrm{CH}_{3}$ were high, the binding free energy between the peptide and PMMA resin was high. Therefore, Table 2 shows that $\mathrm{W}, \mathrm{R}$, and $\mathrm{E}$ were effective as odd-numbered amino acids, and $\mathrm{W}$ and $\mathrm{R}$ were effective as even-numbered amino acids leading to strong binding affinity for PMMA resin. Thus, the design guideline was obtained.

Next, we made the effective peptides identified with the above design guidelines and evaluated their binding affinities for the PMMA resin. Since the experiments with peptide samples were carried out in water, the stabilities of the peptides in water were taken into account. Specifically, if the same amino acids are lined up at neighboring positions, they become entangled when floating in water. For example, when the sequence of a peptide was RWRWRWR, four arginines (Rs) were lined up at neighboring odd-numbered positions, and three tryptophans (Ws) were lined up at neighboring even-numbered positions. In this case, entanglement resulted, as shown in Fig. 7a. On the other hand, when the sequence was RWWRRWW, the amino acids $\mathrm{R}, \mathrm{W}, \mathrm{R}$, and $\mathrm{W}$ were lined up at oddnumbered positions, and $\mathrm{W}, \mathrm{R}$, and $\mathrm{W}$ were lined up at even-numbered positions. In this case, because the same amino acids were not lined up at neighboring positions, entanglement did not result, as shown in Fig. 7b. Therefore, the latter sequence (RWWRRWW) was preferred over the former sequence (RWRWRWR).

In addition, as shown in Fig. 5, the main chain of the peptide attached to the resin had a zigzag structure, whereas it may have had a different structure, such as a spiral structure, in water away from the resin surface. We obtained (a)

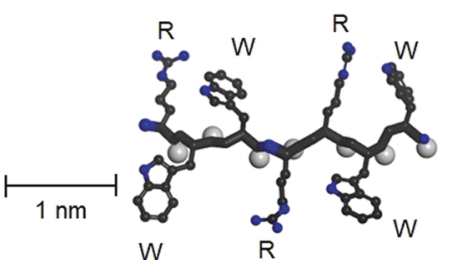

(b)

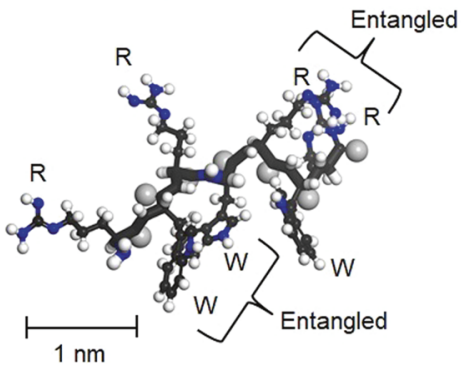

(c)

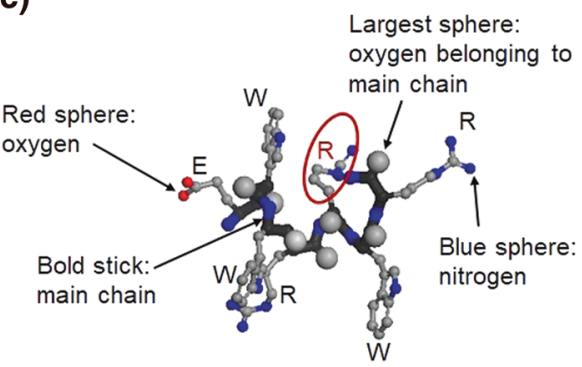

EWWRRWR (main chain: helix-like structure) $\checkmark$ Replace R with P

EWWRPWR (main chain: zig-zag structure)



Fig. 7 Structures of peptides in water: a entangled structure of RWRWRWR, b nonentangled structure of RWWRRWW, and $\mathbf{c}$ effectiveness of the use of $\mathrm{P}$ (proline) in stabilizing the zigzag structure of a main chain in peptides

simulation results showing that the zigzag structure was stabilized, even in water, by adding proline $(\mathrm{P})$ to the peptide. As shown in Fig. 7c, by replacing the 5th $\mathrm{R}$ of EWWRRWR with $\mathrm{P}$ to make it EWWRPWR, the stable structure was changed from spiral to zigzag, even if the peptide originally had a spiral structure in water away from the resin surface. From such simulations, three types of peptides (RWWRPWW, EWWRPWR, and RWWRPWR) were found to have stable zigzag structures in water as well as strong binding affinities with PMMA resin, as shown in Fig. 6. As a representative simulation result, the top view of the RWWRPWW/PMMA interface, which had the strongest binding affinity, is shown in Fig. 8, where the stabilized zigzag structure of the peptide is seen. 


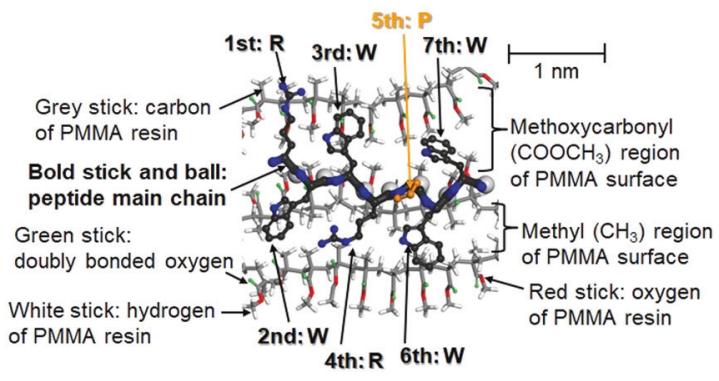

Fig. 8 Top view of the RWWRPWW/PMMA interface

SPR experiments were conducted with these three promising peptides (RWWRPWW, EWWRPWR, and RWWRPWR). In the case of ELWRPTR, which is listed at the top of Table 1 and has the largest binding free energy in Table 1, the association rate and dissociation rate in reference [21] were calculated from the rates of increase and decrease in the graph shown in Fig. 9a. However, in the case of the three peptides (RWWRPWW, EWWRPWR, and RWWRPWR) we proposed, the binding affinities were too strong, and dissociation was not observed in the results shown in Fig. 9b-d, so the proportions of the species shown on right side of the graphs did not decrease. It is thought that the force of solution flow and thermal fluctuation energy due to temperature were not large enough to peel these strongly adhesive peptides from the resin surface. By applying flows of water in molecular dynamics simulations, we confirmed that these three peptides were not dissociated from the PMMA resin and that the other peptides were dissociated, as shown in the simulation visualizations in Fig. 9a-d. Thus, it was not possible to obtain the experimental values of binding free energy for the three strongly adhered peptides. However, it was confirmed that the binding affinities of these three peptides were sufficiently strong to prevent dissociation from PMMA resin. Therefore, simulation-based MI technology is effective for designing peptides with strong binding affinities.

\section{Conclusions}

MI technology based on molecular dynamics simulation was applied to the design of peptides with strong binding affinities for PMMA resin. Binding affinities (binding free energies) obtained with molecular simulations agreed well with experimental values with a prediction error within $10 \%$. From analyses of simulation data with the responsesurface method (Kriging method), it was found that arginine (R) and tryptophan (W) exhibited strong binding to the methoxycarbonyl groups and methyl groups that are the main substituents of PMMA resin and were effective for improving the adhesion strength with the resin. It was also (a)
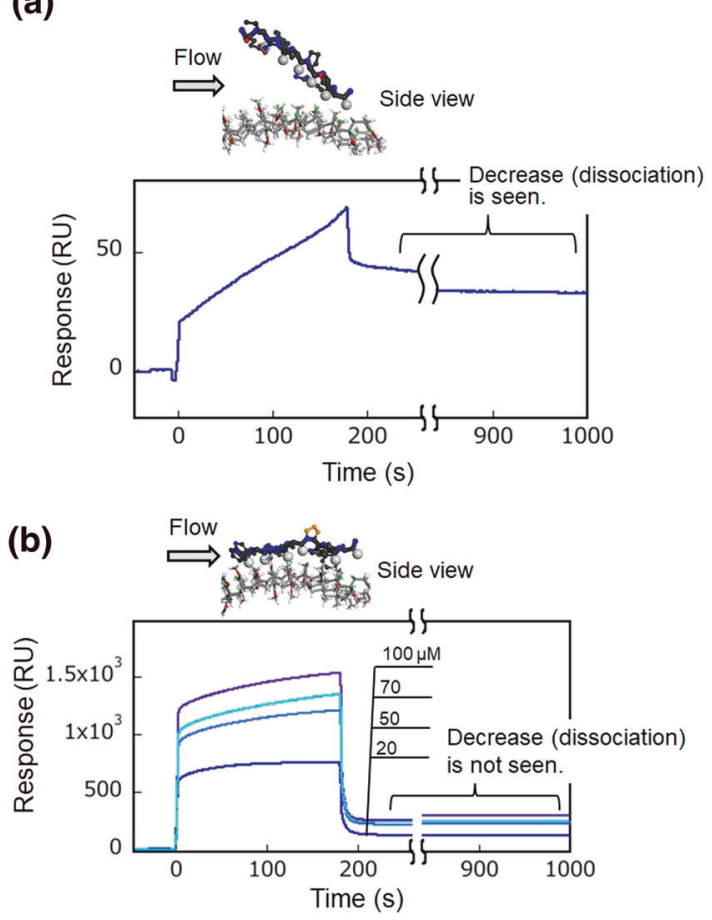

(c)

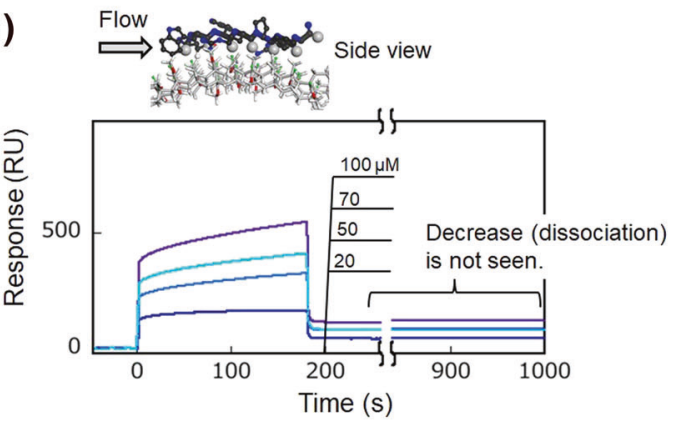

(d)



Fig. 9 Experimental results of SPR measurements for a ELWRPTR, b RWWRPWW, c EWWRPWR, and d RWWRPWR with flow simulation visualization

found that proline $(\mathrm{P})$, which stabilizes the flat zigzag structure of the peptides, improved the binding affinity. Based on these results, three peptides (RWWRPWW, EWWRPWR, and RWWRPWR) were selected as promising candidates. SPR experiments showed that the binding 
affinities of these three peptides for PMMA resin were sufficiently strong to prevent dissociation. From these results, MI technology is considered effective for designing adhesive peptides.

Acknowledgements The authors greatly thank Prof. M. Okochi and Dr M. Tanaka (Tokyo Institute of Technology) for help with SPR measurements.

Author contributions Tomio Iwasaki and Masashi Maruyama conducted molecular dynamics simulations and carried out materials informatics design. Tatsuya Niwa, Toshiki Sawada, and Takeshi Serizawa made experimental researches.

\section{Compliance with ethical standards}

Conflict of interest The authors declare no competing interests.

Publisher's note Springer Nature remains neutral with regard to jurisdictional claims in published maps and institutional affiliations.

Open Access This article is licensed under a Creative Commons Attribution 4.0 International License, which permits use, sharing, adaptation, distribution and reproduction in any medium or format, as long as you give appropriate credit to the original author(s) and the source, provide a link to the Creative Commons license, and indicate if changes were made. The images or other third party material in this article are included in the article's Creative Commons license, unless indicated otherwise in a credit line to the material. If material is not included in the article's Creative Commons license and your intended use is not permitted by statutory regulation or exceeds the permitted use, you will need to obtain permission directly from the copyright holder. To view a copy of this license, visit http://creativecommons. org/licenses/by/4.0/.

\section{References}

1. Urata S, Nakamura N, Aiba K, Tada T, Hosono H. How fluorine minimizes density fluctuations of silica glass: molecular dynamics study with machine-learning assisted force-matching potential. Mater Des. 2020;197:109210.

2. Umeno $Y$, Kitamura $T$, Date $K$, Hayashi $M$, Iwasaki $T$. Optimization of interatomic potential for $\mathrm{Si} / \mathrm{SiO}_{2}$ system based on force matching. Comput Mater Sci. 2002;25:447-56.

3. Sun H, Mumby SJ, Maple JR, Hagler AT. An ab initio cff 93 all atom force field for polycarbonates. J Am Chem Soc. 1994;116:2978-87.

4. Yamamoto K, Kawaguchi D, Sasahara K, Inutsuka M, Yamamoto S, Uchida K, et al. Aggregation states of poly(4-methylpentene-1) at a solid interface. Polym J. 2019;51:247-55.

5. Wang Y-C, Zhang J-F, Chiu M-H, Li J-H, Jui C-Y, Yang T-H, et al. Molecular-weight and cooling-rate dependence of polymer thermodynamics in molecular dynamics simulation. Polym J. 2021;53:455-62.

6. Heinz H, Lin T-J, Mishra RK, Emami FS. Thermodynamically consistent force fields for the assembly of inorganic, organic, and biological nanostructures: the interface force field. Langmuir. 2013;29:1754-65.

7. Koda T, Toyoshima T, Komatsu T, Takezawa Y, Nishioka A, Miyata K. Ordering simulation ofhigh thermal conductivity epoxy resins. Polym J. 2013;45:444-8.
8. Nagumo R, Shimizu A, Iwata S, Mori H. Molecular dynamics study of the molecular mobilities and side-chain terminal affinities of 2-methoxyethyl acrylate and 2-hydroxyethyl methacrylate. Polym J. 2019;51:365-70.

9. Yamazaki K, Nakao A, Suzuki N, Fujiki M. Molecular weightdependent physisorption of non-charged poly(9,9-dioctylfluorene) onto the neutral surface of cuboidal $\gamma$-alumina in toluene. Polym J. 2018;50:865-77.

10. Car R, Parrinello M. Unified approach for molecular dynamics and density-functional theory. Phys Rev Lett. 1985;55:2471-4.

11. Iwasaki T. Design of ceramic materials with strong adhesion to resin with a combination of orthogonal array and response-surface method. J Soc Mater Sci Jpn. 2018;67:479-86.

12. Iwasaki $\mathrm{T}$. Technique for efficiently selecting metal film with strong adhesion to resin with the combination of orthogonal array and response-surface method. J Soc Mater Sci Jpn. 2017;66:427-34.

13. Iwasaki T. Efficient optimum design of metal with strong adhesion to ceramics with a combination of orthogonal array and response-surface method. J Soc Mater Sci Jpn. 2018;67:803-10.

14. Mahmud MAP, Huda N, Farjana SH, Asadnia M, Lang C. Recent advances in nanogenerator-driven self-powered implantable biomedical devices. Adv Energy Mater 2018;8:1-25. https://doi.org/ 10.1002/aenm.201701210.

15. Hassler C, Boretius T, Stieglitz T. Polymers for neural implants. Polym Phys. 2011;49:18-33. https://doi.org/10.1002/polb.22169.

16. Goddard JM, Hotchkiss JH. Polymer surface modification for the attachment of bioactive compounds. Prog Polym Sci. 2007;32: 698-725.

17. Chouirfa H, Bouloussa H, Migonney V, Falentin-Daudré C. Review of titanium surface modification techniques and coatings for antibacterial applications. Acta Biomater. 2019;83:37-54.

18. Serizawa T, Matsuno H, Sawada T. Specific interfaces between synthetic polymers and biologically identified peptides. J Mater Chem. 2011;21:10252-60.

19. Sawada T, Mihara H, Serizawa T. Peptides as new smart bionanomaterials: molecular-recognition and self-assembly capabilities. Chem Rec. 2013;13:172-86.

20. Sawada T, Mihara H, Serizawa T. Preparation of biocomposite soft nanoparticles composed of poly(propylene oxide) and the polymer-binding peptides. Bioconj Chem. 2015;26:2002-15.

21. Serizawa T, Sawada T, Matsuno H. Highly specific affinities of short peptides against synthetic polymers. Langmuir. 2007;23:11127-33.

22. Iwasaki $T$. Technology for designing metal film with strong adhesion to hydrocarbon-chain-based soft resin by use of orthogonal array and molecular simulation. J Soc Mater Sci Jpn. 2016;65:182-9.

23. Iwasaki T. Design of metal film with strong adhesion to resin by use of L9 orthogonal array and molecular dynamics simulation. J Soc Mater Sci Jpn. 2011;60:856-61.

24. Iwasaki T. Molecular dynamics study on the effect of lattice mismatch on adhesion strength between organic materials and metals. J Soc Mater Sci Jpn. 2009;58:257-61.

25. Iwasaki T, Miura H. Analysis of adhesion strength of interfaces between thin films using molecular dynamics technique. J Mater Res. 2001;16:1789-94.

26. Iwasaki T. Molecular dynamics study of adhesion strength and diffusion at interfaces between interconnect materials and underlay materials. Comput Mech. 2000;25:78-86.

27. Iwasaki T. Molecular dynamics study of diffusion and atomic configuration in layered structures for $\mathrm{Al}$ circuit interconnects. Comput Mech. 1999;24:148-54.

28. Woodcock LV. Isothermal molecular dynamics calculations for liquid salts. Chem Phys Lett. 1971;10:257-61.

29. Nose S. A unified formulation of the constant temperature molecular dynamics methods. J Chem Phys. 1984;81:511-9. 
30. Hoover WG. Canonical dynamics: equilibrium phase-space distributions. Phys Rev A. 1985;31:1695.

31. Parrinello $M$, Rahman A. Polymorphic transitions in single crystals: a new molecular dynamics method. J Appl Phys. 1981; 52:7182.

32. Ray D, Gokey T, Mobley DL, Andricioaei I. Kinetics and free energy of ligand dissociation using weighted ensemble milestoning. J Chem Phys. 2020;153:154117-35.

33. Pan AC, Xu H, Palpant T, Shaw DE. Quantitative characterization of the binding and unbinding of millimolar drug fragments with molecular dynamics simulations. J Chem Theory Comput. 2017;13:3372-7.
34. Woo HJ, Roux B. Calculation of absolute protein-ligand binding free energy from computer simulations. Proc Natl Acad Sci. 2005;102:6825-30.

35. De Jong DH, Schäfer LV, De Vries AH, Marrink SJ, Berendsen HJC, Grumüller H. Determining equilibrium constants for dimerization reactions from molecular dynamics simulations. J Comput Chem. 2011;32:1919-28.

36. Wanasundara SN, Krishnamurthy V, Chung SH. Free energy calculations of gramicidin dimer dissociation. J Phys Chem B. 2011;115:13765-70

37. Woldu AS, Mai J. Computation of the bond dissociation enthalpies and free energies of hydroxylic antioxidants using the $a b$ initio Hartree-Fock method. Redox Rep. 2012;17:252-74. 